\title{
The effect of palm oil supplementation on growth and carcass composition of growing lambs
}

\author{
M Hilmi, AR Alimon, M Hair-Bejo \\ Department of Animal Science, Universiti Pertanian Malaysia, Serdang 43400 Selangor, Malaysia
}

Palm oil is considered as a cheap source of energy supplementation in a commercial teed for sheep. However there is a scarcity of report on the effect of oil supplementation on the growth performance of lambs and their carcass composition. Therefore this would be the objective of the study.

Fifteen weaner lambs which live weight ranged from 15 to $18 \mathrm{~kg}$ were divided into three diet groups and placed in individual pens. They were all fed with common basal diet consisting of ad libitum of urea-treated paddy straw and a commercial feed concentrate at the rate of $200 \mathrm{~g}$ per head per day (Alimon, Azila and Saparin, 1993, Proc XVI MSAP Conf, 88-89). While Diet $A$ animals received no other supplements, Diet B and Diet $\mathrm{C}$ animals were, respectively, supplemented with $20 \mathrm{~g}$ and $40 \mathrm{~g}$ of palm oil per animal per day for a duration of 12 weeks. At the end of the feeding trial, the animals were fasted for $24 \mathrm{~h}$ and then slaughtered by exanguination of the neck. The carcases were dressed, halved and the right sides were dissected into three major carcass components ; namely, muscles, fat and bone, according to procedure of Butterfield (1963, Symp on Carcass Composition and Appraisal of Meat Animals, CSIRO Melbourne, Doc 4-1).
The result in the table below shows that increasing the amount of energy in the feed by increasing the level of palm oil, significantly improved the average daily gain $(P<0.05)$ of the lambs but the body composition was not significantly different. The empty body weight at slaughter was higher for Diet $\mathrm{C}$ suggesting that energy supply may not be sufficient to promote maximum growth in Diet $A$. This could indicate the energy level in the diets was adequate to deposit the necessary fat in the carcass while the excess fat may be deployed to the non carcass parts as storage fat as indicated by the tendency for animals on high level of palm oil supplementation to have lower the dressing percentage.

It can be concluded that the palm oil can be used as an energy supplement with the advantage of improving average daily gain and maintaining low level of carcass fatness.

Acknowledgements: Thanks are due to Mr Moorty, Shafee and Salawati for looking after the animals and laboratory and carcass analyses. This study was funded by Universiti Pertanian Malaysia IRPA Project 50333.

\begin{tabular}{|c|c|c|c|c|}
\hline Parameters & Diet A & Diet B & Diet C & sig \\
\hline Number of lambs & 5 & 5 & 5 & \\
\hline Initial liveweight $(\mathrm{kg})$ & 17.3 & 17.7 & 17.4 & ns \\
\hline ADG $(g / d) 12$ weeks & 42.1 & 48.3 & 66.2 & $* *$ \\
\hline Dressing \% & 47.3 & 47.5 & 46.9 & ns \\
\hline Total fat $\%$ & 7.16 & 7.04 & 7.72 & ns \\
\hline Total muscle \% & 64.0 & 64.9 & 64.9 & ns \\
\hline Total bone \% & 27.8 & 26.8 & 26.3 & ns \\
\hline
\end{tabular}

